\title{
Egg and cows' milk allergy in children
}

\author{
R P K FORD AND D M FERGUSSON \\ Department of Paediatrics, Christchurch Clinical School of Medicine, Christchurch Hospital, New Zealand
}

SUMMARY The relationships between a history of egg or cows' milk allergy, positive skin tests to these allergens, and atopic illness were examined in a sample of 126 children. Positive skin tests were found more often in children with a history of egg or cows' milk allergy than in children with no such history. 40 children suspected of being allergic to egg or milk, by history or by positive skin tests, were tested by double-blind food challenge. 54 challenges were given to these children, and $26(49 \%)$ were positive. Children suspected of being allergic to egg had a greater incidence of positive challenges than children suspected of having milk allergy. Children with both a present history of food allergy and a positive skin test for that allergen were more likely to have positive challenges than children having only one of these indicators. Most children with positive challenges failed to satisfy Goldman's criterion of a minimum of three positive challenges because of the severity of their reactions. Less stringent criteria are needed for the diagnosis of food allergy in children who are particularly sensitive to food allergens.

The diagnosis of food allergy is a contentious issue. Various studies have shown that a patient's history of food allergy or even open food challenges may be misleading since his conditioned psychological response may confuse his physiological response. ${ }^{1-2}$ It has been suggested that accurate detection of the condition requires the use of double-blind methods, ${ }^{2}$ but results of only three such studies have been published. ${ }^{1-3}$

This paper examines two issues relating to the diagnosis of food allergy: firstly, the relationship between previous history of alleged food allergy, atopic illness, and reactions to skin tests; secondly, the incidence of positive food challenges among children suspected of being allergic on the basis of a present history or a positive skin test.

\section{Materials and methods}

Sample. The sample comprised 126 children. 44 were children with suspected food allergy and 82 were an unselected control group of outpatients or convalescing inpatients. Ages ranged from 3 months to 12 years, with a median age of 3 years.

Measurements. The study was conducted in two stages. Initially, mothers of all children were interviewed on a structured questionnaire which examined the child's history of adverse reactions to eggs and cows' milk, history of asthma, and history of eczema. Each child was tested with skin pricks using whole hen's egg and whole cows' milk aller- gens (Bencard testing solutions 5201 and 5202) and a control solution. Weal size was measured with a Bencard skin testing gauge. 53 children had either a present history of egg or cows' milk allergy, or showed a positive skin test. This group was selected for double-blind food challenge.

\section{Method of challenge}

There were three challenge foods: placebo, egg, and milk. The base of the challenge foods consisted of $50 \mathrm{ml}$ ProSobee liquid (Mead Johnson) to which flavouring had been added. This was made up to $100 \mathrm{ml}$ with water for placebo, half a hen's egg and water for egg, and reconstituted skim cows' milk powder for milk. $6 \mathrm{~g}$ lactose was added to the placebo and egg drinks to control for lactose intolerance.

For a week before the challenge, and throughout it, each child remained on a diet free of any foods suspected of causing allergic reactions.

The child was first given a single-blind challenge with either egg or milk as appropriate, the dose being slowly increased until symptoms developed or the whole drink had been taken. The child remained under observation for several hours and if serious symptoms were observed, the trial was stopped. Children who continued the trial were tested for a 10-day period. Each day each child was given a flavoured soya bean drink by his mother. On 8 days the drink was a placebo and on 2 days it contained either milk or egg. For each day of the trial the mother kept a precoded diary describing symptoms displayed by the child (rash, vomiting, diarrhoea, 
abdominal pain, wheezing), any other symptoms, the time the drink was taken, the amount ingested, and whether there were any dietary infringements.

Owing to lack of patient compliance, only 40 of the 53 eligible children were tested. 27 were tested with egg, and 27 with milk, 14 children being tested with both.

\section{Definitions}

(1) A skin prick test was considered positive if the weal diameter was at least $3 \mathrm{~mm}$ greater than the control weal. ${ }^{4}$

(2) A food challenge was considered positive if one of the following was satisfied: (a) If, on the singleblind challenge, the child displayed such severe symptoms (that is, laryngeal oedema, angioedema, protracted vomiting) that it was deemed dangerous to continue the trial. Three milk challenges and 7 egg challenges produced reactions of this severity. (b) If, during the double-blind challenge, the child showed such severe symptoms (that is, vomiting, choking, angioedema) as to make it unwise to continue the challenge. Four milk and 7 egg challenges were stopped for this reason. (c) If, on the completion of the double-blind challenge, the child showed at least 2 symptoms (that is, skin rash, angioedema, choking, coughing, vomiting, abdominal pain, diarrhoea, wheezing) on active days over and above the symptoms shown on the 3 placebo days (taken as the second day after the active days).

This method of classification was not based on strict double-blind criteria as not all children completed the double-blind challenge trial. However, the clinical symptoms that forced the trial to be stopped in each case were related to the food allergen and occurred within 3 hours of its administration.

\section{Results}

Relationship between skin tests and previous history of food allergy. Table 1 shows the proportions of children with positive skin tests to the allergens, cross-tabulated by the child's previous history of alleged food allergy, asthma, and eczema. The likelihood of a positive skin test varied with previous history of food allergy and with the child's propensity to atopic illness. Specifically, children with a positive history of egg allergy had 5 times the rate of positive skin tests to egg as children without such a history. Children with a previous history of milk allergy had approximately 4 times the rate of positive tests to milk as children with no such history. Children with a history of asthma or eczema had an increased rate of positive skin tests to both allergens. This was
Table 1 Incidence of positive skin tests by child's history

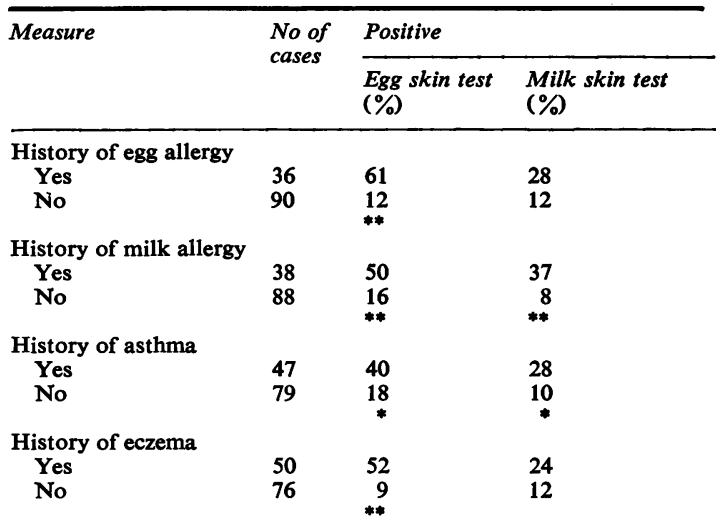

*Denotes significant difference at 0.05 level $\left(x^{2}\right.$ test). **Denotes significant difference at 0.001 level $\left(\chi^{2}\right.$ test).

particularly evident for children with eczema, who had 5 times the rate of positive egg skin tests compared with children without eczema.

As it was possible that the associations between previous history of food allergy and skin test results were artificial owing to the common effects of both asthma and eczema, these associations were controlled statistically using partial correlation methods. This analysis showed that the previous history of food allergy remained related to skin tests. The correlation between previous history of egg allergy and a positive egg skin test was $+0.50(\mathrm{P}<0.001)$ and when effects of asthma and eczema were taken into account this correlation fell to $+\mathbf{0} \cdot 32$ $(\mathrm{P}<0.001)$. For cows' milk, the corresponding correlation between previous history and a positive skin test was $+0.36(P<0.001)$, being reduced to $+0.34(\mathrm{P}<0.001)$.

Results of food challenge. Table 2 gives the proportions of children with positive egg and milk challenges. For each allergen this proportion is cross-tabulated by the number of positive indicators of food allergy that the child had at the beginning of the trial (history or positive skin test, or both). 26 (49\%) of the 54 challenges were positive. However, the likelihood of a positive challenge varied with the type of allergen and the number of positive indicators. $63 \%$ of egg challenges were positive. This varied from $42 \%$ for children with only one positive indicator at the beginning of the trial, to $80 \%$ for children having two positive indicators. The difference between the two groups is significant $(P<0.05)$. Only $33 \%$ of milk challenges were positive but there was some variation in the risk of a positive 
Table 2a Egg challenge results

\begin{tabular}{llcc}
\hline Indicators & $\begin{array}{l}\text { No of } \\
\text { cases }\end{array}$ & \multicolumn{2}{l}{ Positive } \\
\cline { 3 - 4 } & & No & $\%$ \\
\hline $\begin{array}{c}\text { Either a positive history or a } \\
\text { positive skin test for egg }\end{array}$ & 12 & 5 & 42 \\
$\begin{array}{c}\text { Both a positive history and a } \\
\text { positive skin test for egg }\end{array}$ & 15 & 12 & 80 \\
Total & 27 & 17 & 63 \\
\hline
\end{tabular}

Fisher's exact test $\mathbf{P}<0.05$.

Table 2b Cows' milk challenge results

\begin{tabular}{lccc}
\hline Indicators & $\begin{array}{l}\text { No of } \\
\text { cases }\end{array}$ & \multicolumn{2}{l}{ Positive } \\
\cline { 4 - 5 } & & No & $\%$ \\
\hline $\begin{array}{l}\text { Either a positive history or a } \\
\text { positive skin test for milk }\end{array}$ & 19 & 5 & 26 \\
$\begin{array}{l}\text { Both a positive history and a } \\
\text { positive skin test for milk }\end{array}$ & 8 & 4 & 50 \\
Total & 27 & 9 & 33 \\
\hline
\end{tabular}

Fisher's exact test $P>0.05$.

challenge: children with two positive indicators had a $50 \%$ chance of returning a positive challenge, in contrast to the $26 \%$ chance for children with only one positive indicator. With these small numbers this difference is not statistically significant.

\section{Discussion}

The results showed that there were significant associations between a previous history of egg or cows' milk allergy and positive skin prick tests to egg and milk. Children with a previous history of food allergy more often showed positive skin tests than control children. There was also a relationship between previous history of atopic illness and skin tests: children with asthma or eczema showed positive skin tests more often than nonatopic children. However, the correlation between the history of food allergy and skin tests could not be explained by the common effects of atopic disease, since when the effects of asthma and eczema were controlled the correlations remained significant.

Food challenge of children with either a history of alleged food allergy or a positive skin test to egg or milk showed that a substantial proportion were allergic to egg or milk or both. Just under half the number of challenges were positive. The likelihood of a positive challenge varied with the allergen tested and with the child's clinical indicators at the beginning of the trial. Children suspected of being allergic to egg returned a far greater proportion of positive challenges than children suspected of being allergic to milk: nearly two-thirds of egg challenges were positive compared with only one-third of milk challenges. Over $80 \%$ of children who had both a present history of alleged egg allergy and a positive egg skin test returned a positive challenge. In contrast, $42 \%$ of those with only one of these indicators returned a positive challenge. Similar but nonsignificant differences were observed with the milk challenges. The findings suggest that previous history of allergic response and positive skin tests are prognostic of food allergy. The risk of a child being allergic given one or more of these indicators ranges from $26 \%$ for children with one indicator of milk allergy, to $80 \%$ for children with two indicators of egg allergy.

Finally, the results show the need to develop realistic criteria for assessing the effects of food challenge. Goldman et al. ${ }^{5}$ have suggested that a minimum of three positive challenges are required to substantiate a diagnosis. In this study these criteria were unworkable as they could be met by only 5 of the 26 children with a positive challenge. In the remaining 21 children reactions were of such severity as to demand the termination of the trial before all three challenges were given.

We thank Dr B Taylor, paediatrician, and Dr B Broom, clinical immunologist, for guidance, Miss $\mathrm{E}$ Jordan, dietitian, for preparing the challenge foods, Miss K Read for secretarial help, and Mead Johnson for supplying the ProSobee.

This research was supported by a grant from the Canterbury Medical Research Foundation.

\section{References}

1 Loveless M H. Milk allergy. A survey of its incidence; experiments with a masked ingestion test. J Allergy Clin Immunol 1950; 21 : 489-99.

2 May C D. Objective clinical and laboratory studies of immediate hypersensitivity reactions to foods in asthmatic children. J Allergy Clin Immunol 1976; 58: 500-15.

3 Maslansky L, Wein G. Chocolate allergy. A double blind study. Conn.Med 1971; 35: 5-9.

4 Bock S A, Buckley J, Holst A, May C D. Proper use of skin tests with food extracts in diagnosis of hypersensitivity to food in children. Clin Allergy 1977; 7: 375-83.

5 Goldman A S, Anderson D W, Jr, Sellers W A, Saperstein S, Kniker W T, Halpern S R. Milk allergy. I. Oral challenge with milk and isolated proteins in allergic children. Pediatrics 1963; 32: 425-43.

Correspondence to Dr R P K Ford, Department of Gastroenterology, Royal Children's Hospital, Flemington Road, Parkville, Victoria 3052, Australia.

Received 24 July 1979 